\title{
Utilization Patterns and User Characteristics of an Ad Libitum Internet Weight Loss Program
}

\author{
Martin Binks ${ }^{1,2}, \mathrm{PhD}$; Trevor van Mierlo ${ }^{3,4}, \mathrm{BA}$ \\ ${ }^{1}$ Binks Behavioral Health, PLLC, Hillsborough, NC, USA \\ ${ }^{2}$ Division of Medical Psychology, Department of Psychiatry and Behavioral Sciences, Duke University Medical Center, Durham, NC, USA \\ ${ }^{3}$ Evolution Health Systems Inc, Toronto, ON, Canada \\ ${ }^{4}$ Dalla Lana School of Public Health, University of Toronto, Toronto, ON, Canada
}

\section{Corresponding Author:}

Martin Binks, PhD

Binks Behavioral Health, PLLC

2801 Canter Drive

Hillsborough, NC 27278

USA

Phone: 19197325524

Fax: 19197325524

Email: mbinks@binksbehavioralhealth.com

\begin{abstract}
Background: The Internet holds promise for the delivery of evidence-based weight loss treatment to underserved populations. However, most studies do not reflect the more naturalistic and common ad libitum, or freely at will, use of the Internet. Randomized clinical trials, for example, typically include at least some direct contact with participants and often have restrictive selection criteria. There is a paucity of research examining utilization patterns of online weight loss programs, particularly in the rapidly expanding direct-to-consumer arena.
\end{abstract}

Objectives: To examine self-reported characteristics (age, body mass index [BMI], gender), behaviors, and Internet site utilization patterns of a sample of users of a direct-to-consumer ad libitum Internet weight loss program.

Methods: This study is based on analysis of archival data from the initial 15 weeks of an ongoing, free, evidence-based, direct-to-consumer Internet weight loss program, the Healthy Weight Center, which included standard information about nutrition, fitness, and behavioral strategies; monitoring tools; and moderated support group message boards. Participants encountered the program through self-directed Internet searches and anonymously registered to utilize the site. Self-reported user characteristics and electronically tracked utilization data were extracted from existing program data, compiled, and examined. Pearson correlations were computed to examine the association of program utilization with age and BMI. One-way analysis of variance (ANOVA) was used for gender comparisons.

Results: We examined data from the first 204 adult users of the program who were classified as either overweight (BMI 25 to $<30 \mathrm{~kg} / \mathrm{m}^{2}$ ) or obese $\left(\mathrm{BMI} \geq 30 \mathrm{~kg} / \mathrm{m}^{2}\right.$ ). The mean age of participants was 42.0 years (SD 11.7), 81.9\% (167/204) were women, and mean BMI was $32.01 \mathrm{~kg} / \mathrm{m}^{2}$ (SD 6.26). The percent of participants who used program tools was as follows: $13.7 \%$, meal planner; $10.8 \%$, nutrition lookup: $17.6 \%$, activity $\log ; 14.2 \%$, journal; and $22.1 \%$, weight tracker. Participants also used the following educational resources: nutrition, $13.2 \%$; fitness, $6.4 \%$; and behavioral, $7.4 \%$. Of the personal self-assessments available through the program, $57.8 \%$ of participants assessed personal barriers, and 50.5\% assessed relationship with food. Only $7.8 \%$ used the support group message boards. No significant associations between site utilization and age, gender, or BMI were found. Reasons for wanting to lose weight were: health, 87\%; appearance, 74\%; mobility, 44\%; doctor recommendation, $23 \%$; and spouse/friend suggested, $12 \%$. The age participants reported first becoming overweight was young adulthood, $31 \%$; late adulthood, 28\%; childhood, 22\%; adolescence, 17\%; and as a toddler, 3\%. Self-perceived factors contributing to weight gain were lack of exercise for $70 \%$ of participants, emotions for $62 \%$, overeating for $61 \%$, and slow metabolism for $33 \%$.

Conclusions: Internet weight loss programs reach many people who cannot access traditional treatment. However, users appear not to be optimally utilizing key aspects of the weight loss intervention, such as education, monitoring, and support. This study provides insight into the patterns of ad libitum use of an online weight loss program across multiple treatment-related domains in a naturalistic Internet environment. 
(J Med Internet Res 2010;12(1):e9) doi: 10.2196/jmir.1347

\section{KEYWORDS}

Weight loss; obesity; Web-based; self-help; Internet; utilization; intervention

\section{Introduction}

The Internet holds promise for the delivery of weight loss programs to underserved populations. However, the majority of published Internet weight loss research is from controlled clinical trials [1]. Clinical trial-based eHealth interventions may face challenges to generalizability relating to the inclusion of direct personal contact and extensive screening that is not part of a more naturalistic ad libitum, or freely at will, use of the Internet, as is the case with most Internet users' experiences $[2,3]$. It also has been shown that eHealth programs are susceptible to poor utilization and attrition, which further limits their utility [4].

Internet-based weight loss research typically focuses on treatment outcomes, overall attrition rates, site logins and nutrition/weight tracking without consideration of the degree to which the therapeutic intervention (eg, accessing assessments, educational content, and support groups) was delivered [5]. If we are to develop effective Internet weight loss programs, we must ensure that the core treatment elements are being delivered. Individual tailoring of content through user self-assessments may be an effective approach to improving utilization. By using brief online questionnaires to assess the range of issues that may impact weight loss we may be able to deliver more personally relevant content to each individual user that addresses their particular area(s) of concern. Scientifically rigorous (ie, meta-analytic) review of research evaluating the efficacy of this approach is unavailable; however, narrative reviews have suggested that self-assessments may be too time consuming and thus unacceptable to the user [6,7]. Therefore, consideration of the degree to which participants use interactive self-assessments represents an important step in determining their feasibility.

In this analysis of archival data we examine website utilization data gathered from a free, evidence-based, anonymously utilized, direct-to-consumer weight loss program that includes nutrition, fitness, and behavioral information; self-assessments; monitoring tools; and moderated support group message boards.

\section{Methods}

\section{Setting and Program Description}

The Healthy Weight Center [8] is a free access, evidence-based $[9,10]$ Internet weight loss program that provides nutrition, fitness, and behavioral information; monitoring tools; interactive assessments with individually tailored feedback; and moderated support group message boards (see Multimedia Appendix 1). The Internet intervention is based on a review of design principles and consumer testing across multiple eHealth platforms (ie, smoking cessation, depression, panic disorder, and problem drinking) and usability testing of this and our other eHealth platforms [11]. The program utilizes free-form matrix design, that is, all program elements are available to every user.

The program also provides an online program guide to facilitate full utilization of the program elements.

The program was available for free to anyone having access to the World Wide Web from any geographic region of the world. There was no advertising or promotion of the program. A link to the program was added to the Evolution Health corporate site [12], and potential users could also encounter the program using publicly available Internet searches. The period of data collection for this study was the initial 15-week period of program availability from May to Sept 2008. The program continues to be available to the public. There was no formal recruitment for the program. To enroll, users completed the online registration process consisting of 14 questions that included weight, height, date of birth, gender, email address, occupation and questions relating to weight and dieting history. Registrants were also asked to electronically endorse the program disclosure agreement explaining that data were being collected anonymously and that this unidentifiable information would be used for research purposes.

\section{Subjects}

The subjects of this study were the first 204 individuals who registered for the online weight loss program and who met the following inclusion criteria: (1) 18 years or older, (2) body mass index (BMI) classified as overweight (BMI 25 to $<30 \mathrm{~kg} / \mathrm{m}^{2}$ ) or obese (BMI $\geq 30 \mathrm{~kg} / \mathrm{m}^{2}$ ); (3) completion of all questions contained in the online registration process; and (4) endorsement of the program disclosure agreement.

Of these 204 participants, $18.1 \%$ (37/204) were men, and $81.9 \%$ (167/204) were women. The mean age of the participants was 42.0 (SD 11.7) years; 44.4 (SD 12.6) years for men, and 41.5 (SD 11.5) years for women. The mean BMI of the participants was $32.0(\mathrm{SD} 6.3) \mathrm{kg} / \mathrm{m}^{2} ; 31.2$ (SD 5.2) kg/m² for men, and $32.2(\mathrm{SD} 6.5) \mathrm{kg} / \mathrm{m}^{2}$ for women.

Mean weight of the participants was 89.4 (SD 19.9) kg; 99.8 (SD 16.8) kg for men, and 86.9 (SD 19.3) kg for women. All registrants with complete data were included for analysis $(\mathrm{N}=204)$. Thirty-three subjects were excluded for missing (BMI) data.

\section{Data Collection}

Data for the 204 registrants meeting the inclusion criteria were extracted from the existing Healthy Weight Center database. All online registration questionnaires for the Healthy Weight Center program adhered to international privacy guidelines $[13,14]$. Procedures were in accordance with the Helsinki Declaration of 1975, as revised in 2008 [15]. Because the study was based on the use of unidentifiable archival data, the study was determined to be exempt from further review.

Personal characteristics and behaviors were based on registrants' self-reported responses to the online questionnaires. We used website analysis tools to determine the extent of program 
utilization for each participant. Utilization of each individual program element was defined as accessing that program element at least once: educational information (nutrition, fitness, and behavioral), self-assessments (personal barriers and relationship with food) [16], monitoring tools (weight tracker, exercise tracker, journal, and nutrition lookup), and the moderated support groups.

\section{Statistical Analysis}

Personal characteristics/behaviors and utilization data were tabulated as percent reporting. To explore the influence on site utilization of age (eg, younger individuals may be more Internet savvy and thus engage in higher utilization) and BMI (eg, heavier individuals may be more motivated and thus engage in higher utilization), Pearson correlations were computed. One-way analysis of variance (ANOVA) was used to consider gender differences in demographic factors (ie, age, BMI) and program utilization.

\section{Results}

\section{Gender}

One-way ANOVA revealed no significant differences by gender for age $\left(F_{1,202}=1.8, P=.18\right)$, BMI $\left(F_{1,202}=0.7, P=.40\right)$, and program utilization $\left(F_{1,202}=0.4, P=.53\right)$.

\section{Program Utilization, Age, and BMI}

The mean number of program elements utilized was 2.7 (SD 3.9). Pearson correlations revealed no significant correlations of program utilization with age $(\mathrm{N}=204 ; r=-.02 ; P=.78)$ or BMI $(\mathrm{N}=204 ; r=-.02 ; P=.81)$.

Table 1. Utilization of program elements $(\mathrm{N}=204)$

\begin{tabular}{ll}
\hline Program Element (see Multimedia Appendix 1) & Utilization \\
\hline Meal planner & $\mathrm{n}(\%)$ \\
Nutritional data look up tool & $28(13.7)$ \\
Activity log & $22(10.8)$ \\
Journal & $36(17.6)$ \\
Weight tracker & $29(14.2)$ \\
Nutrition education & $45(22.1)$ \\
Fitness education & $27(13.2)$ \\
Behavioral education & $13(6.4)$ \\
Support group message board & $15(7.4)$ \\
Personal barriers assessment & $16(7.8)$ \\
Relationship with food assessment & $118(57.8)$ \\
\hline
\end{tabular}

\section{Discussion}

Internet weight loss programs that provide evidence-based intervention can reach many individuals who have limited access to traditional treatments. However, website users may not be utilizing Web-based weight loss resources optimally. The standard of care in weight management involves nutrition,

\section{Utilization Patterns}

Site utilization data for all users $(\mathrm{N}=204)$ based on accessing each tool at least one time is presented in Table 1. Site tools used for monitoring key weight loss behaviors (meal planner, nutrition lookup, activity log, journal and weight tracker) were not highly utilized. Similarly, educational materials (nutrition, fitness, and behavioral) and support group message boards were not accessed by the majority of users. However, interactive assessments (personal barriers and relationship with food), showed relatively higher utilization.

\section{Personal Characteristics/Behaviors}

Data concerning personal characteristics/behaviors were compiled for all participants $(\mathrm{N}=204)$. When participants were asked to indicate all applicable reasons for wanting to lose weight $87 \%$ (177/204) endorsed health; 74\% (151/204), appearance; 44\% (89/204), mobility; 23\% (47/204), doctor recommended; and 12\% (24/204) indicated that a friend/spouse suggested they lose weight. In terms of the age that users reported first becoming overweight, 31\% (63/204) reported young adult onset, $28 \%(57 / 204)$ reported late adult onset, $22 \%$ (44/204) reported onset during childhood, 17\% (34/204) reported adolescent onset, and 3\% (6/204) reported first becoming overweight as a toddler. Of the factors that participants believed contributed most to their weight gain, the most frequently endorsed items were: lack of exercise, endorsed by $70 \%$ (143/204); emotions, endorsed by $62 \%$ (126/204); overeating, endorsed by $61 \%(124 / 204)$; and slow metabolism, endorsed by $33 \%(67 / 204)$. and use of personal support [9,10]. In our study of ad libitum use of a Web-based weight loss program, participants did not take full advantage of these essential treatment elements.

In our Internet weight loss program, interactive self-assessments (eg, personal barriers and relationship with food) were more highly utilized than the similarly interactive weight/fitness 
tracking tools and journaling. This finding suggests that interactivity alone was not likely responsible for higher utilization. A distinguishing feature of our interactive self-assessments was the promise of personally relevant feedback, which may have made these exercises particularly appealing to the user. Evidence from previous studies suggests that tailoring interventions to individuals may be an effective tool in improving health behavior, but concerns arise about the acceptability to participants of completing the self-assessments that are needed to tailor content $[6,7,17]$. Our findings suggest that users may actually prefer using interactive self-assessments as compared with other program elements that were available to them in our study (monitoring tools, educational content, support group message boards). This finding highlights the need for architects of Internet-based programs to explore increasing the use of interactive exercises to tailor the user experience in ways that increase personal relevance. This may be preferable to relying on predetermined blocks of educational content to deliver the necessary treatment elements. Furthermore, identifying relevant baseline personal characteristics/behaviors of users may also deserve further consideration. For example, in this study, the majority of users reported that health, mobility, and appearance were important contributors to their decision to engage in the program. Perhaps by tailoring interactive assessments and content to areas of relevance to the individual user, we may be able to approximate the more typical in person health care experience.

Finally, while we did not consider this directly in our study, the literature suggests that utilization of therapeutic program elements may be increased through novel approaches to enhancing the user experience and including incentives such as rewards for completing exercises. Architects of future
Internet-based weight loss programs should consider these strategies $[18,19,20]$.

\section{Strengths and Limitations}

This study provides insight into how individuals utilize Internet resources in a natural setting as opposed to a clinical trial environment. The relatively fewer barriers to enrollment, based on this program's open availability on the Internet in comparison with the barriers to entry that are typical of Internet-based clinical trials, is a particular strength. Also, few studies have examined the utilization of specific program elements (eg, educational materials, tools, and assessments), focusing instead on broader criteria such as the total number of log-ins. Limitations of our study include the small sample size in comparison with other studies of natural use of Internet health programs and lack of information about users' geographic area (eg, country of residence) each of which may limit generalizability. Another limitation is the lack of information about treatment outcomes and our inability to determine the frequency (multiple accessing of each element) or extent (amount of time spent using each element) with which elements of the program were used, as our data was based on accessing each element at least once. These factors are important considerations for future studies.

\section{Summary}

This study provides insight into potential strategies for optimizing program design to improve utilization of core treatment elements of Internet-based weight loss programs. This is a necessary step to ensure quality when widely disseminating weight loss treatments. Future studies should include detailed analysis of utilization patterns and their relationship to both short- and long-term outcomes.

\section{Conflicts of Interest}

Dr. Binks has acted as a paid consultant to Evolution Health Systems Inc, Toronto, ON, Canada/San Francisco, CA, USA, which owns the Healthy Weight Center software among other eHealth platforms. Trevor van Mierlo is the CEO of Evolution Health Systems Inc.

\section{Multimedia Appendix 1}

Screenshots from the Healthy Weight Center Internet site illustrating the program elements outlined in Table 1

\section{[PPT file (Microsoft Powerpoint), 1380 KB-Multimedia Appendix 1]}

\section{References}

1. Kirbis-Weinstein PK. A review of weight loss programs delivered via the internet. J Cardiovascular Nursing 2006;2(4):251-258 [FREE Full text]

2. Cunningham JA, van Mierlo T. Methodological issues in the evaluation of Internet-based interventions for problem drinking. Drug Alcohol Rev 2009 Jan;28(1):12-17. [Medline: 19320670]

3. Bonell C, Oakley A, Hargreaves J, Strange V, Rees R. Assessment of generalisability in trials of health interventions: suggested framework and systematic review. BMJ 2006 Aug 12;333(7563):346-349 [FREE Full text] [Medline: 16902217] [doi: $10.1136 /$ bmj.333.7563.346]

4. Eysenbach G. The law of attrition. J Med Internet Res 2005 Mar;7(1):e11 [FREE Full text] [Medline: 15829473] [doi: 10.2196/jmir.7.1.e11]

5. Jonasson J, Linné Y, Neovius M, Rössner S. An Internet-based weight loss programme -- a feasibility study with preliminary results from 4209 completers. Scand J Public Health 2009 Jan;37(1):75-82. [Medline: 18684784] [doi: $\underline{10.1177 / 1403494807085066]}$ 
6. Neville LM, O'Hara B, Milat A. Computer-tailored physical activity behavior change interventions targeting adults: a systematic review. Int J Behav Nutr Phys Act 2009;6(1):30 [FREE Full text] [Medline: 19490649] [doi: 10.1186/1479-5868-6-30]

7. Lustria MLA, Cortese J, Noar SM, Glueckauf RL. Computer-tailored health interventions delivered over the Web: review and analysis of key components. Patient Educ Couns 2009 Feb;74(2):156-173. [Medline: 18947966] [doi:

10.1016/j.pec.2008.08.023]

8. Healthy Weight Center. URL: http://www.healthyweightcenter.net/ [accessed 2010-02-01] [WebCite Cache ID 5nECOVnS3]

9. Wing RR, Tate DF. Endotext.com 2002. Behavior modification for obesity. In: Caro JF, editor. Obesity. URL: http://www. endotext.org/obesity/obesity17/obesityframe17.htm [accessed 2010-02-01]

10. ; National Heart, Lung and Blood Institute, National Institutes of Health, U.S. Department of Health and Human Services. The Clinical Guidelines on the Identification, Evaluation and Treatment of Overweight and Obesity in Adults: Evidence Report Sep 1998. URL: http://www.ncbi.nlm.nih.gov/bookshelf/br.fcgi?book=obesity [accessed 2010-02-01]

11. van Mierlo T, Cunningham J. Anonymous Internet-based interventions for problem drinkers: design, development and dissemination. Presented at: 35th Annual Alcohol Epidemiology Symposium of the Kettil Bruun Society; June 5, 2009; Copenhagen, Denmark URL: http://www.kbs2009.dk/abstracts-kbs2009.pdf [accessed 2010-02-01] [WebCite Cache ID 5nEDcRziV]

12. Evolution Health Systems Inc. URL: http://www.evolutionhs.com/programs.aspx [accessed 2010-02-13] [WebCite Cache ID 5nW5plLtf]

13. Office of the Privacy Commissioner of Canada. 2000. Updated 2006. Personal Information Protection and Electronic Documents Act URL: http://www.priv.gc.ca/legislation/02 0601 e.cfm[WebCite Cache ID 5nEGDr6jp]

14. ; U.S. Department of Health \& Human Services. Health Insurance Portability and Accountability Act of 1996. p. 104-191 URL: http://www.hhs.gov/ocr/office/index.html [accessed 2010-02-01] [WebCite Cache ID 5Xfm36ydO]

15. ; World Medical Association. Declaration of Helsinki: ethical principles for medical research involving human subjects. 7th revision. Presented at: 59th WMA General Assembly; 2008; Seoul, Korea URL: http://infomed.mds-ev.de/sindbad.nsf/ ddf5e481ed777582002567cb004313b9/75521880dcc4739dc12574ee00376317/\$FILE/DoH_6Rev_SEOUL_2008-10.pdf [accessed 2010-02-13] [WebCite Cache ID 5nWFlChiw]

16. Cappelleri JC, Bushmakin AG, Gerber RA, Leidy NK, Sexton CC, Karlsson J, et al. Evaluating the Power of Food Scale in obese subjects and a general sample of individuals: development and measurement properties. Int J Obes (Lond) 2009 Aug;33(8):913-922. [Medline: 19506564] [doi: 10.1038/ijo.2009.107]

17. de Vries H, Kremers SPJ, Smeets T, Brug J, Eijmael K. The effectiveness of tailored feedback and action plans in an intervention addressing multiple health behaviors. Am J Health Promot 2008;22(6):417-425. [Medline: 18677882]

18. Danaher BG, McKay HG, Seeley JR. The information architecture of behavior change websites. J Med Internet Res 2005;7(2):e12 [FREE Full text] [Medline: 15914459] [doi: 10.2196/jmir.7.2.e12]

19. Wing RR, Epstein LH, Marcus M, Shapira B. Strong monetary contingencies for weight loss during treatment and maintenance. Behav Ther 1981;12(5):702-710. [doi: 10.1016/S0005-7894(81)80141-4]

20. Volpp KG, John LK, Troxel AB, Norton L, Fassbender J, Loewenstein G. Financial incentive-based approaches for weight loss: a randomized trial. JAMA 2008 Dec 10;300(22):2631-2637 [FREE Full text] [Medline: 19066383] [doi: 10.1001/jama.2008.804]

Edited by G Eysenbach; submitted 03.09.09; peer-reviewed by M Wanner, J Kabukoba, L Ware; comments to author 27.09.09; revised
version received 17.02.10; accepted 21.02.10; published 29.03.10
Please cite as:
Binks M, van Mierlo T
Utilization Patterns and User Characteristics of an Ad Libitum Internet Weight Loss Program
J Med Internet Res 2010;12(1):e9
URL: $\underline{\text { http://www.jmir.org/2010/1/e9/ }}$
doi: $\underline{10.2196 / j m i r .1347}$
PMID: $\underline{20350926}$

(C) Martin Binks, Trevor van Mierlo. Originally published in the Journal of Medical Internet Research (http://www.jmir.org), 29.03.2010. This is an open-access article distributed under the terms of the Creative Commons Attribution License (http://creativecommons.org/licenses/by/2.0/), which permits unrestricted use, distribution, and reproduction in any medium, provided the original work, first published in the Journal of Medical Internet Research, is properly cited. The complete bibliographic information, a link to the original publication on http://www.jmir.org/, as well as this copyright and license information must be included. 